\title{
O movimento feminista na produção acadêmica dos cursos de pós-graduação em Serviço Social
}

\author{
The feminist movement in the academic \\ production of postgraduate courses in Social Work
}

\author{
Maria Lúcia Duriguetto \\ Professora associada da Faculdade de Serviço Social da Universidade Federal \\ de Juiz de Fora/MG, Brasil. Bolsista CNPO. maluduriguetto@gmail.com
}

\begin{abstract}
Verônica Medeiros Alagoano
Graduada e mestre em Serviço Social pela Faculdade de Serviço Social (UFJF). Atualmente, docente no Curso de Serviço Social da Universidade Federal de Ouro Preto (Ufop), Minas Gerais, Brasil. veronica.ufop16@gmail.com
\end{abstract}

Resumo: O artigo trata da produção acadêmica dos cursos de pós-graduação em Serviço Social sobre o movimento feminista. As produções são analisadas tendo como referência o tratamento, pela tradição marxista, do movimento feminista e dos conceitos de gênero, patriarcado, relações sociais de sexo e divisão sexual do trabalho. Evidencia-se incipiente tematização desses conceitos, o que expressa a necessidade de um maior investimento na produção de conhecimento sobre o feminismo e o movimento feminista.

Palavras-chave: Feminismo. Movimento feminista, Produção teórica. Serviço Social.
Abstract: The article deals with the academic production of Post-Graduation courses in Social Work on the feminist movement or the struggle of women in mixed movements. The productions are analyzed with reference to the treatment, by the Marxist tradition, of the emergence of the feminist movement and the concepts of gender, patriarchy, social relations of sex and the sexual division of labor. There is an incipient approach of these themes by the profession, which expresses the need for a greater investment in the production of knowledge about feminism and the feminist movement.

Keywords: Feminism. Feminist movement. Theoretical production. Social Work. 


\section{Premissas de análise sobre a questão feminista e o movimento feminista}

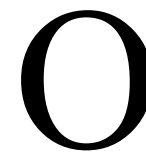

debate do feminismo se configura em um campo de diferentes perspectivas, tendências e disputas, as quais se expressam numa diversidade de compreensão do que vem a ser o feminismo, suas principais lutas e reivindicações. Pretende-se, aqui, apresentar o debate feminista desenvolvido no campo da tradição marxista. Tendo em vista as divergentes correntes teóricas que sustentam o feminismo, a escolha do marxismo se deu pela fundamental contribuição dessa tradição para a emancipação das mulheres, perspectiva que não é constatada no feminismo liberal e pós-moderno (e outras correntes). Essa tradição nos permite compreender o modo de produção capitalista (MPC), que têm como eixo estruturante a apropriação privada dos meios de produção e do produto do trabalho humano - que Marx denomina de trabalho excedente - , fundamento das desigualdades sociais que se expressam em todas as esferas da reprodução da vida social.

É no bojo dessas desigualdades que compreendemos as questões que tocam a realidade das mulheres. É sabido que algumas dessas questões são anteriores à sociedade burguesa; contudo, vale ressaltar que o MPC associa e articula antigas e novas contradições para manter o processo de valorização do capital, ainda que em novas bases.

Para Saffioti (1976, p. 32), tratar da dependência e da subalternidade da mulher, já presente em outros modos de produção e potencializada no MPC, requer trazer para a análise a categoria trabalho. Ao abordar o trabalho feminino, explicita que as mulheres da classe trabalhadora sempre trabalharam, seja na produção agrícola, manufatura, indústria, trabalho doméstico e, ainda, "enquanto a família existiu como uma unidade de produção, as mulheres e as crianças desempenharam um papel econômico fundamental" (Idem).

Entretanto, foi a própria necessidade do capital, de acordo com o desenvolvimento das forças produtivas, que definiu como e em que medida as mulheres foram integradas à sociedade. A condição subalterna da mulher, 
herança de outros modelos de produção, é absorvida para confluir numa superexploração das mulheres das camadas populares, as quais foram integradas ao trabalho industrial. Delas foi extraído o mais alto nível de exploração da mais-valia absoluta, por meio da ampliação da jornada de trabalho e de salários inferiores aos dos homens.

Desde o socialismo utópico, a libertação do gênero feminino foi tomada como relevante. Contudo, para o marxismo, a possibilidade de emancipação do gênero humano está na superação da sociedade de classes cujo elemento fundante é a propriedade privada, que tem na apropriação do trabalho excedente seu elemento essencial. Desse modo, somente com a superação do MPC o homem pode recuperar sua essência, realizar-se e desenvolver suas capacidades. Assim, para esta tradição, a emancipação da mulher coincide com o processo de humanização do gênero humano. A subordinação das mulheres não explica o funcionamento do MPC; de outro modo, é a partir das determinações essenciais desse MPC que podem ser evidenciadas as raízes de opressão/subordinação feminina.

São as situações de exploração, dominação, opressão e discriminação colocadas às mulheres que fazem eclodir o movimento feminista. Desde sua gênese, o movimento apresenta uma pluralidade de perspectivas teórico-políticas e interventivas. De diferentes formas e a partir dos processos sócio-históricos particulares das formações sociais, as reivindicações das mulheres se espraiaram e conformaram diversas perspectivas e lutas. Destacamos as vinculadas à tradição marxista, em que a luta das mulheres se volta para a emancipação humana, reconhecendo que a libertação das mulheres coincide com a superação do sistema patriarcal-capitalista-racista, e as vinculadas à tradição liberal, nas quais o feminismo se limita à luta pela cidadania burguesa.

Souza-Lobo (2011, p. 212) destaca que a Europa foi palco das primeiras lutas feministas que pautavam avanços no campo da emancipação política, com reivindicações voltadas para os direitos historicamente negados às mulheres. Concomitante a essas lutas, junto ao movimento operário e partidos socialistas, também se consolidava as lutas classistas, com denúncias 
das condições de vida, trabalho e violência sexista por parte dos patrões. Somado a isso, denunciavam a discriminação que vivenciavam no próprio meio sindical e a opressão presente na família operária. ${ }^{1}$

O final da década de 1960 se tornou um importante marco do reascenso da luta feminista, que questiona a subordinação da sexualidade feminina à maternidade, a problematização do lugar que as mulheres ocupam na sociedade, nas relações cotidianas e nas organizações políticas.

No Brasil, apesar de ter sido na década de 1970 que o feminismo alcançou expressão com movimentos de mulheres organizados em torno de reivindicações por políticas e serviços públicos, pela redemocratização e direitos, ressaltamos que as mulheres sempre estiveram presentes nos processos de luta e resistência do país, ainda que o feminismo e suas pautas não se expressassem como a luta central. ${ }^{2}$

O movimento feminista brasileiro emergiu em sintonia com o mundial, com a atuação em reivindicações por direitos e relacionados às desigualdades entre os sexos, sem entretanto questionar o MPC, como também movimentos vinculados à luta de classes, com pautas voltadas para as condições de vida das trabalhadoras sintonizadas com as lutas do movimento sindical operário.

No percurso histórico do movimento feminista no país, é preciso ressaltar o seu forte processo de institucionalização ou "onguização" nos anos finais da década de 1980, que impactou regressivamente as formas de mobilização e de lutas feministas. Cisne (2014, p. 148). Este processo será redimensionado na década de 2000, período em que surgem a Marcha Mundial das Mulheres (MMM), o Movimento Mulheres em Luta (MML), a Articulação de Mulheres Brasileiras (AMB) e o Movimento de Mulheres Camponesas (MMC). Tais movimentos e organizações foram e são de grande relevância por assumirem

1. Para elucidar os desenvolvimentos do movimento feminista em diferentes países da Europa e nos Estados Unidos, ver Saffioti (1976); González (2010); Souza-Lobo (2011). Para uma apreensão das lutas e conquistas do feminismo na Revolução Russa, ver Goldman (2014).

2. Abordagens do movimento feminista na particularidade brasileira podem ser encontradas em Saffioti (1976), Pinto (2003), Souza-Lobo (2011) e Cisne (2014). 
um caráter anticapitalista e por se tornarem as principais referências da luta feminista crítica e classista no Brasil na atualidade.

Nos processos de organização e luta do movimento feminista em diferentes formações sócio-históricas, também emergiram diversas perspectivas ideológicas, políticas e teóricas, que se tornaram um importante legado para compreendermos a luta das mulheres na contemporaneidade. Da pluralidade de temáticas, conceitos e categorias, destacamos o debate de gênero, relações sociais de sexo, patriarcado e divisão sexual do trabalho. Também destacamos a influência das premissas pós-modernas devido à sua influência no movimento feminista em geral.

O termo gênero foi amplamente difundido a partir de 1975 e, no Brasil, foi na década de 1990 que o termo passou a ser utilizado de forma recorrente. O termo, como observa Scott, emerge num contexto de "mudança de paradigma científico" em que as análises macroestruturais nas ciências sociais são colocadas em xeque. Esse posicionamento crítico acerca da ciência moderna significou o alinhamento de parte do momento feminista à perspectiva pós-moderna, ${ }^{3}$ que tem como um de seus elementos a recusa das teorias que apontam as causas e os nexos causais da emergência e do desenvolvimento da exploração/dominação nos marcos do capitalismo. Scott (1995, p. 73) evidencia essa perspectiva na negativa da paridade entre os termos classe, raça e gênero. Para a autora, a categoria classe se restringe a determinações econômicas a partir de um momento histórico, sendo que raça e gênero não permitem a mesma compreensão.

A repercussão do uso do termo gênero nos estudos feministas deve-se ao questionamento da naturalização das relações sociais, numa perspectiva biologicista. Contudo, como ressalta Saffioti (2015, p. 115), há aqui uma

3. Para Wood (2003, p. 219-20), um elemento que unifica as teorias pós-modernas é a "ênfase na diversidade, na 'diferença', no 'pluralismo'”. As premissas pós-modernas compreendem a realidade social de forma fragmentada, focada nas diferenças e nas subjetividades individuais. Nesse sentido, não se pode mais prospectivar solidariedade de classes, mas identidades fluidas dos "novos movimentos sociais", que desenvolvem lutas focadas nas "outras identidades e contra opressões, movimentos relacionados à raça, ao gênero, à etnicidade, à sexualidade etc.”. 
dicotomia entre gênero e sexo, em que sexo seria o aspecto biológico e gênero uma construção social, e ressalta: "a elaboração social do sexo deve mesmo ser ressaltada, sem, contudo, gerar a dicotomia sexo e gênero, um situado na biologia, na natureza, outro, na sociedade, na cultura".

Outro questionamento da autora a respeito da utilização do termo refere-se à atribuição de gênero no aspecto social, dissociada do corpo. Também empregado de forma indiscriminada, o termo se torna substitutivo de mulheres, sem evidenciar as relações de desigualdade e opressão por elas vivenciadas.

Ainda na perspectiva de Saffioti, gênero e classes sociais possuem gêneses distintas. Gênero é anterior às classes e passa por um conjunto de transformações para se adequar à emergência daquelas, bem como reitera a importância de problematizarmos a questão racial junto às contradições de classe e gênero. Para a autora, essas contradições, de forma distinta, se fundem, tornando-se um nó de determinações que "tornam a situação das mulheres mais complexas" (Idem, p. 123).

Em concordância com Saffioti, Cisne (2013, p. 83) destaca que o conceito de gênero ofusca o elemento histórico da categoria sexo e corpo, provocando uma dicotomia entre sexo e gênero, além de obscurecer categorias como classe e raça. Nesse sentido, tanto as teorias pós-modernas como o uso indiscriminado do conceito de gênero não contribuem para uma análise de totalidade das relações sociais e das particularidades que envolvem a vida das mulheres.

Para o campo de análise que desenvolve suas reflexões sobre as relações de exploração, dominação e opressão a partir da tradição marxista, as concepções pós-modernas estão na contramão da emergência do movimento feminista ao focarem demasiadamente nas diferenças. Como afirma Cisne (2013, p. 87),

é certo que o gênero não possui apenas sexo, mas possui raça, etnia, orientação sexual, idade etc. No entanto, dentro desta sociedade, não podem ser vistas isoladas de suas macrodeterminações, pois, por mais que o gênero 
unam as mulheres, a homossexualidade una os gays e lésbicas, a geração una as(os) idosas(os) ou jovens, a classe irá dividi-las(os) dentro da ordem do capital.

Deste modo, sem hierarquizar ou desconsiderar as questões atinentes à raça/etnia, gênero, geração e sexualidade, as reflexões ancoradas na tradição marxista perspectivam e prospectivam um campo ético-político de atuação dos movimentos sociais a partir de uma perspectiva emancipatória, no campo da luta de classes. Situar as lutas nesse campo significa apontar que as opressões vivenciadas na sociabilidade do capital se tornam estruturais, sendo necessária uma transformação radical das relações sociais de produção para uma verdadeira emancipação humana. Como afirma Cisne (2013, p. 88), “o que se defende não é a neutralização ou anulação das diferenças, mas a percepção de que o movimento feminista deve convergir para os aspectos político e social. Do contrário, só a fragmentam e pulverizam as mulheres".

Dada a complexidade do conceito de gênero, sua variação de sentido e vasto uso, estudiosas do feminismo marxista materialista francófono vão justificar a necessidade da substituição do termo gênero pela categoria "relações sociais de sexo". A expressão ganha relevância na década de 1980, vinculada a estudos marxistas que abordam a divisão sexual do trabalho. Tal expressão remete às relações sociais mais amplas fundamentadas em relações sociais de classe. Relacionada à divisão sexual do trabalho, a utilização do conceito em questão torna-se relevante por demarcar uma hierarquia entre os sexos, o que não se pode verificar na utilização do conceito de gênero. Além do mais, expõe de forma explícita a contradição de classe, configurando-se, desta forma, como importante conceito para o feminismo. Portanto, o termo possibilita compreender a questão da mulher no antagonismo de classe, bem como permite a incorporação do estudo das "relações sociais de sexo" relacionadas às "dimensões de 'raça' e classe" Cisne (2014, p. 67). Esta análise é também presente nas produções de Saffioti e Kergoat, que destacam a consubstancialidade entre as relações sociais de sexo, raça e classe que 
conformam um nó nas quais tais relações são coextensivas, se produzem e se reproduzem mutuamente.

Outro conceito recorrente nos estudos feministas é o de patriarcado. Para Saffioti (2015), a utilização desse conceito evoca relações que se estruturam de forma hierarquizada e desigual. O patriarcado se consolida com a propriedade privada, sendo constituído historicamente. Assim, as diferenças entre os sexos não são imutáveis, o que implica o descarte de análises "biologicistas", "a-históricas" e "cultural-simbólicas": "O patriarcado ou ordem patriarcal de gênero [...], só se aplica a uma fase histórica, não tendo a pretensão da generalidade nem da neutralidade, e deixando propositalmente explícito o vetor da dominação-exploração. (Idem, p. 139).

Outro debate central para o feminismo refere-se à divisão sexual do trabalho, essencial para a compreensão do mecanismo de exploração do modo de produção capitalista sobre o trabalho feminino, que além de dividir o trabalho entre homens e mulheres, o hierarquiza de forma a subalternizar o trabalho classificado como "naturalmente" feminino em detrimento do trabalho "naturalmente" masculino. Para compreendermos a particularidade da inserção das mulheres no processo produtivo sob a sociabilidade do capital é necessário "desomogeneizar" a classe trabalhadora ou, como ressalta Souza-Lobo (2011), é necessário considerar que a “classe operária tem dois sexos".

A inserção da mulher no processo produtivo faz parte da reprodução ampliada do capital que se apropria do trabalho feminino de forma subsidiária e delegando às mulheres funções que garantem a reprodução social com baixa renumeração ou sem remuneração, por se caracterizar como naturais e vinculadas à esfera privada. Contudo, mesmo na esfera pública a inserção das mulheres se efetiva de forma subsidiária e com baixa remuneração. Nesse sentido, vale destacar que o patriarcado não se estrutura apenas na esfera privada, como destaca Saffioti (2015, p. 135), "as diferenças entre o público e o privado estão [...] profundamente ligad[as] e parcialmente mesclad[as]".

Para Kergoat (2009, p.71), "relações sociais de sexo e divisão sexual do trabalho são dois termos indissociáveis e que formam epistemologicamente 
um sistema". Assim, as relações sociais de sexo podem ser caracterizadas pelos quatro elementos a seguir:

a relação entre os grupos assim definidos é antagônica; as diferenças constatadas entre as práticas dos homens e das mulheres são construções sociais, e não provenientes de uma causalidade biológica; esta construção social tem uma base material e não é unicamente ideológica em outros termos, a "mudança de mentalidades" jamais acontecerá espontaneamente se estiver desconectada da divisão de trabalho concreta - podemos fazer uma abordagem histórica e periodizá-la; estas relações sociais se baseiam antes de tudo em uma relação hierárquica entre os sexos, trata-se de uma relação de poder, de dominação.

Ao evidenciarmos os principais termos do debate feminista, podemos constatar uma disputa que se dá tanto no plano teórico como na prática interventiva dos movimentos feministas. Tal constatação reforça a necessidade de afirmação de um feminismo classista e de horizonte emancipatório. Nesse sentido, entendemos que, apesar das contribuições do termo gênero para o debate feminista, é preciso problematizar sua utilização indiscriminada. Como afirma Saffioti (2015), esse termo se tornou mais palatável por não explicitar de pronto as contradições entre as classes sociais, portanto, pretensamente neutro. Assim, como reitera Cisne (2014), o emprego de "relações sociais de sexo" possibilita, principalmente por sua perspectiva teórico-política materialista, a explicitação da dominação masculina inserida no fundamento estrutural de classe, sendo necessária uma radical alteração dessa estrutura para a libertação feminina. Da mesma forma, concordamos com a utilização da categoria patriarcado, já que sua utilização, ao contrário de gênero, demarca a dominação/exploração/opressão vivenciada pelas mulheres, ou seja, além de evidenciar a supremacia masculina, indica que a opressão de sexo é estruturante à ordem societária do capital. O conceito de divisão sexual do trabalho também é central por trazer para a análise a forma de organização social do trabalho, marcada, fortemente, pelo sexo, uma vez que o trabalho realizado pelas mulheres ganha atributos considerados naturais para desqualificá-lo e desvalorizá-lo. 
Em suma, tais categorias representam um importante acúmulo dos estudos feministas, que permitem apontar a necessidade de o feminismo se reafirmar como movimento social articulado à luta de classes, o que não significa desconsiderar as lutas possíveis e necessárias nos marcos do capitalismo, mas, também, afirmar que a libertação das mulheres só será possível com a erradicação desse modo de produção.

Assim como o feminismo apresenta diferentes perspectivas teóricas e prático-políticas, podemos notar essa mesma variação na produção acadêmica do Serviço Social, que a seguir trataremos.

\section{Serviço Social e feminismo: os termos do debate}

A pesquisa sobre a produção do conhecimento dos programas de pós-graduação — área Serviço Social — no período compreendido entre 1985 e 2014 sobre as temáticas acima desenvolvidas, resultou no encontro de 22 pesquisas, ${ }^{4}$ sendo nove que abordavam o movimento feminista e treze que apresentavam a luta das mulheres em movimentos sociais mistos e organizações. As análises aqui apresentadas compreendem treze produções (nove dissertações e quatro teses), as quais estavam disponíveis para acesso on-line . $^{5}$ Observa-se a concentração das produções a partir da década de 2000, sendo apenas uma dissertação desenvolvida em 1998. A maioria das dissertações e teses (doze) realizou pesquisa de campo, sendo uma de caráter documental. E, em termos de perspectiva teórico-metodológica, a maioria das produções, exceto três, se situa no campo de análise da tradição marxista.

4. Para nosso estudo, selecionamos as teses/dissertações que abordam o movimento feminista destacadas na pesquisa coordenada por Duriguetto (2017) sobre a produção do conhecimento nos cursos de pós-graduação — área Serviço Social — sobre movimentos sociais e Serviço Social (1985-2011). A partir dos termos movimento de mulheres, movimento feminista, lutas sociais das mulheres, feminismo, organizações feministas, organização de mulheres, ampliamos a busca no banco de dados da Capes e nos sites dos programas de pós-graduação até 2014. Ver Alagoano (2016).

5. Medeiros (1998), Fischer (2004), Barros (2005), Santos (2006), Almeida (2008), Lusa (2009), Souza (2009), Diniz (2010), Morales (2010), Rocha (2012), Cisne (2013), Inácio (2013), Silva (2013). 
Das treze produções que analisamos, sete versam sobre movimentos feministas e seis sobre a luta das mulheres em movimentos mistos e/ou organizações: uma tese busca compreender o significado do trabalho feminino e sua inserção na Associação de Produtores Rurais - Movimento de Mulheres Trabalhadoras Rurais (MMTR); uma tese problematiza a construção da identidade de gênero na luta pela terra organizada pela Comissão Pastoral da Terra (CPT); duas dissertações e uma tese abordam a luta das mulheres no Movimento dos Trabalhadores Rurais Sem-Terra (MST) e duas dissertações analisam o Movimento de Mulheres Camponesas (MMC). Desta forma, podemos notar um relevante número de estudos (oito) que abordam a luta das mulheres no campo.

Das outras teses e dissertações, uma dissertação tematiza a luta das mulheres em duas organizações não governamentais (ONGs): Centro de Documentação e Informação Coisa de Mulher (Cedoicom) e o Grupo de Mulheres Felipa de Souza; uma dissertação estuda as relações de poder entre homens e mulheres no Movimento de União dos Bairros (MUB) e outra aborda as ações do movimento feminista para combater a violência contra a mulher no Fórum de Mulheres de Pernambuco (FMPE). Somente duas teses se dedicam a uma abordagem teórica da questão do feminismo e, também, analisam alguns movimentos feministas contemporâneos, como a Marcha Mundial das Mulheres (MMM), MMC, Articulação de Mulheres Brasileiras (AMB), União Brasileira de Mulheres (UBM), Movimento Mulheres em Luta (MML) e Grupo Pão e Rosas.

O estudo das produções acima referidas, além de expressar ainda um tímido investimento de produção de conhecimento da profissão sobre a temática, nos permite expressar uma compreensão difusa do significado da categoria "movimento social", ${ }^{6}$ que inclui, sem distinção fóruns, ONGs, movimentos de bairros, associações. Em outro polo estão as teses e dissertações que se centram em análises sobre movimentos sociais relevantes no

6. Para uma sumária apreensão do debate marxista dos movimentos sociais, ver Montãno e Duriguetto (2011). 
cenário político da realidade nacional, como o MST, Movimento de Mulheres Trabalhadoras Rurais, MMC, entre outros. Contudo, apenas cinco das treze produções abordam movimentos feministas auto-organizados, sendo que apenas duas se dedicam aos movimentos feministas urbanos de grande relevância nos processos de luta contemporâneos.

Os conteúdos das produções foram analisados a partir dos seguintes eixos temáticos: abordagem teórico-política; conceitos e categorias utilizadas; desafios e limites das organizações e dos movimentos feministas; projetos societários defendidos para as organizações e movimentos feministas; relação do feminismo e das organizações e movimentos feministas com o Serviço Social.

\section{A) A abordagem teórico-política}

Das treze produções analisadas, três vão abordar a luta das mulheres no MST, com destaque na luta das mulheres no contexto da luta pela terra, considerando seu processo histórico no Brasil e o MST como importante movimento social que organiza homens e mulheres na luta pela terra. Observam que é no bojo dessa luta que surgem as demandas por igualdade de gênero e o feminismo no MST. Ademais, é das condições de vida no campo que também revelam disparidades entre os sexos, que a auto-organização das mulheres no movimento irá se tornar uma tática importante para elevar a participação e as conquistas no campo dos direitos sociais. Destaca-se que as reivindicações das mulheres estão associadas à construção de um projeto anticapitalista. É nessa mesma direção que se desenvolve o estudo sobre a CPT.

As três produções sobre o MMC o identificam como movimento feminista e campesino, que se desenvolve pela necessidade de organizar as mulheres do campo para a conquista de direitos historicamente negados, sendo o primeiro deles o reconhecimento como trabalhadoras e sujeitos de direitos previdenciários. Enfatizam, também, a luta por soberania nacional 
encampada pelo movimento, bem como a importância de lutas junto a outros movimentos sociais. Elucidam que o movimento se orienta a partir de princípios como autonomia, perspectiva de classe, construção de relações igualitárias e lutas anticapitalistas. A luta pelo reconhecimento do trabalho das mulheres e de seus direitos previdenciários também é explicitado no estudo do MMTR.

Nos estudos que abordaram a AMB, é destacada a emergência desse movimento como fruto da articulação das mulheres para a IV Conferência das Nações Unidas. A organização, nesse momento, se voltou para as discussões acerca da saúde, violência, participação política, educação e direitos sexuais e reprodutivos. Após a conferência, a AMB se define como organização política feminista, antirracista e não partidária, com o objetivo de conquistar a autonomia para as mulheres, o que supõe a superação da sociedade de classes. São destacados como objetivos permanentes da organização a auto-organização das mulheres, democratização do Estado; democracia interna do movimento; diálogo e aliança com outros movimentos sociais.

Nos estudos da MMM serão destacados a origem do movimento vinculada à marcha de Quebec (Canadá), ação que nos anos 2000 reuniu centenas de mulheres numa marcha pedindo "pão e rosas", por ocasião do dia Internacional das Mulheres, cujo tema era a violência contra as mulheres. Destaca-se que as ações da MMM foram de grande importância para o feminismo no Brasil e que, a partir da década de 1990, embora adquira contornos de forte institucionalização, continua afirmando seu caráter anticapitalista.

Na produção que aborda o MML, a UBM e o Grupo Pão e Rosas, evidencia-se que essas organizações emergem de partidos políticos e centrais sindicais, o que as confere uma vinculação com as lutas gerais dos trabalhadores.

As pesquisas que tratam de associações de bairro, ONGs e associação de trabalhadores rurais focam suas análises na perspectiva de ações diretas e lutas por direitos. Reforçam a necessidade de ampliar a participação das mulheres nas esferas de decisão das organizações e a inclusão de suas pautas. Especificamente o estudo das ONGs destaca a discriminação sofrida pelas 
mulheres lésbicas e negras e as necessárias políticas de inclusão desses sujeitos na sociedade. Nessa mesma direção, o estudo do Fórum de Mulheres de Pernambuco (FMPE) vai ressaltar as ações da organização voltadas para a visibilidade da violência sofrida pelas mulheres, bem como a luta por políticas públicas voltadas para as mulheres.

\section{B) Conceitos e categorias utilizadas}

Para caracterizar a luta das mulheres, há uma recorrência na utilização dos conceitos de gênero, patriarcado e divisão sexual do trabalho. No que se refere ao debate de gênero, cinco produções recuperam as polêmicas da sua utilização indiscriminada e oito se centram nas análises das lutas, desafios e perspectivas dos movimentos e organizações, sem considerar o acúmulo teórico e os debates contemporâneos do movimento feminista.

Há preponderância da discussão das "relações de gênero". O termo aparece em dez produções, com destaque para a participação política das mulheres e a construção da identidade nas lutas. É comum uma parte significativa dessas produções estabelecer uma relação entre gênero e poder, com o objetivo de compreender as desigualdades de gênero nos movimentos e organizações estudadas. Além da utilização do conceito gênero, é notável a problematização acerca das relações de poder, cuja principal referência teórica é Michel Foucault, sem problematizar a perspectiva do autor — notadamente vinculada à perspectiva pós-moderna —, como destaca Saffioti (2015).

Para a abordagem do conceito de gênero, a maioria das produções se referencia em Scott. Exceções podem ser observadas em quatro produções, que aprofundam as questões relativas à utilização do conceito. Estas destacam o uso indiscriminado, a pretensa neutralidade, a ausência da mulher como sujeito, a ambiguidade e a negação das contradições de classe, questões que, como expomos, são fundamentais para compreendermos as limitações da utilização do conceito. 
Há um importante destaque para a categoria patriarcado, que é mencionada em onze produções, tendo por referência as de Saffioti. Foi possível constatar que três delas não discutem teoricamente nem o termo gênero, nem patriarcado. A análise tem como prioridade a questão racial e sexual. Neste sentido, vale destacar a ausência de estudos que relacionem tais questões à luta das mulheres e suas pautas, bem como a abordagem acerca da orientação sexual presente em apenas um estudo, o qual trata das organizações lésbicas negras.

A categoria divisão sexual do trabalho é utilizada em oito produções. Estas compreendem que a divisão social do trabalho também supõe uma divisão sexual, que invisibiliza, naturaliza e desqualifica os trabalhos realizados pelas mulheres, caracterizando-os como feminino. Uma das produções destaca que, além de uma divisão sexual, há uma divisão racial do trabalho, o que intensifica a exploração, dominação e opressão das mulheres não brancas. Entretanto, a análise se centra na ausência do debate sobre o racismo no interior do movimento social analisado (MST) e na ausência das mulheres negras nas esferas organizativas do movimento.

Contudo, apesar da recorrência e do desenvolvimento dos conceitos e categorias que balizaram e vêm balizando o debate do feminismo, constatamos, ainda, uma fragilidade e/ou imprecisão teórica na maioria das produções acadêmicas. Exceções podem ser constatadas no estudo de Cisne (2013), que destaca, entre outros elementos, a necessidade da apreensão das relações de dominação, exploração e opressão da mulher a partir dos conceitos "relações sociais de sexo" e de divisão sexual do trabalho intrínsecos ao modo de produção capitalista-racista-heteronormativo e Inácio (2013), que também vincula a divisão sexual do trabalho ao capitalismo patriarcal.

Há também um grupo expressivo de produções que destaca a divisão entre esfera pública e privada; relações de poder e participação política das mulheres. Destacam que a subordinação da mulher se efetiva nas duas esferas e que na realidade camponesa há uma grande tendência a compreender o trabalho das mulheres como complementar ao do homem. 
Destaca, ainda, a dificuldade de as mulheres ocuparem os espaços públicos, exercício que deve ser priorizado nas e pelas organizações que participam. Também problematiza a simples defesa da inserção da mulher no espaço público e ressalta que, do ponto de vista do movimento feminista, é importante pensar em estratégias que vão além de ocupar espaços institucionais, numa perspectiva de transformação das estruturas de poder. Ressalta que a participação das mulheres em partidos, sindicatos e movimentos sociais se torna uma possibilidade de renovar as práticas políticas dessas organizações. De forma geral, os estudos observam que, apesar de se considerar a importância das mulheres nos movimentos e organizações, ainda há uma débil participação das mesmas, principalmente nas esferas de decisão desses espaços coletivos.

C) Desafios e limites das organizações e dos movimentos feministas

Ao tratarem dos desafios dos movimentos e organizações, das treze pesquisas, seis destacam as conquistas de direitos.

Em relação aos desafios e limites apresentados pelas organizações e movimentos mistos ou feministas, duas produções destacam que os desafios internos dos movimentos e organizações mistas em incorporar as mulheres e suas demandas se expressam na dificuldade de ocuparem espaços de decisão nessas organizações; uma produção problematiza a dificuldade de debates que incorporem as mulheres negras e lésbicas nos movimentos sociais. Problematizações sobre valores culturais patriarcais, concepção de família, mulher e maternidade também são identificados como desafios a ser enfrentados em três pesquisas; em três produções se evidencia o desafio da construção de um feminismo que ultrapasse as demandas relativas aos limites da emancipação política para a necessária construção de processos sócio-organizativos cujo horizonte seja a construção da emancipação humana. Nesse sentido, vale destacar os apontamentos de Cisne (2013) e Inácio (2013). Cisne (2013) ainda aponta outros desafios, como a construção de um programa feminista, a autossustentabilidade, a fragilidade do 
debate teórico do feminismo, a fragmentação do movimento feminista, o enfrentamento ao conservadorismo, a relação das lutas feministas à raça-classe-sexo. Em uma produção tem-se o destaque do enfrentamento da violência contra a mulher como um dos maiores desafios do movimento feminista contemporâneo.

Em todas as produções salienta-se da relevância da inserção da mulher em um movimento social para o despertar da consciência de sua situação de exploração, dominação e opressão, como, por exemplo, o que Cisne (2014) nomina como "consciência militante feminista". O potencial revolucionário das lutas feministas são destaques nos estudos de Silva (2013); Inácio (2013) e Cisne (2014).

D) Projetos societários defendidos para as organizações e movimentos feministas

As perspectivas ético-políticas defendidas para organizações e movimentos feministas aparecem de forma bem difusa e diversa nas produções analisadas. Em quatro estudos, há referência à luta das mulheres articulada à luta de classes, porém não se elucida acerca de um projeto de classe anticapitalista. O que podemos notar é uma perspectiva de luta das mulheres no sentido da ampliação dos direitos sociais, nos limites da cidadania burguesa.

Outras quatro produções vão apresentar a luta das mulheres no campo da participação política, na construção de novas identidades, numa perspectiva de ampliação da cidadania e de direitos. Apenas três produções vão explicitar, de forma consistente, a compreensão de um feminismo classista que objetiva a emancipação humana, sem desprezar a importância das conquistas de direitos para as mulheres. Nessa perspectiva, ressaltam que no modo de produção capitalista as conquistas das mulheres terão sempre os limites impostos pelo capital. Portanto, para uma libertação das mulheres, faz-se necessário uma alteração radical das relações sociais capitalistas. Por isso, destacam a importância do movimento feminista em articular suas lutas, demandas e projetos com outros movimentos sociais, numa perspectiva classista e anticapitalista. 
A defesa de um feminismo emancipatório é encontrada em duas produções, em que tal defesa é tratada centralmente pela via da defesa da cidadania e do direito.

E) Relação do feminismo e das organizações e movimentos feministas com o Serviço Social

Evidencia-se que das treze produções analisadas, sete fazem alusão ao Serviço Social. Apenas uma tem como objeto de estudo o feminismo e sua relação com a profissão, numa associação entre a luta emancipatória feminista e o projeto ético-político profissional. As outras seis produções vão destacar, de forma pontual e pouco desenvolvida, a intervenção da profissão junto aos movimentos sociais, salientando a importância de se fortalecer as demandas das mulheres, principalmente no campo dos direitos e na elaboração de políticas públicas voltadas para as reivindicações das mulheres. Nessas produções, as autoras se referem ao projeto ético-político e ao Código de Ética para justificar a possibilidade de intervenção junto aos sujeitos coletivos.

\section{Indicações conclusivas}

Há uma pluralidade de compreensão acerca do feminismo, que se manifesta em um amplo campo de debate e formas de luta. Reconhecendo tal pluralidade, destacamos como discussões pertinentes e atuais: os conceitos de gênero, relações sociais de sexo, divisão sexual do trabalho e patriarcado. Com uma variação de compreensão e perspectivas, esses conceitos necessitam de uma apreciação cuidadosa para não incorrer em análises que simplificam seu significado e não elucidam as diversas concepções e perspectivas societárias presentes em sua utilização.

Na mesma direção que aponta as produções de Cisne (2014), Inácio (2013) e Silva (2013), compreendemos o movimento feminista como 
movimento social associado à luta geral dos trabalhadores com potencial de transformação radical da sociedade de classes, sem desconsiderar, entretanto, a importância das lutas para ampliação de direitos nos marcos dessa sociedade.

Na análise da produção de conhecimento dos programas de pós-graduação - área Serviço Social —, podemos notar inconsistências no debate presente em grande parte das produções analisadas. Os referidos conceitos, gênero, patriarcado e divisão sexual do trabalho são utilizados, em boa parte das produções, sem apresentar seus diversos significados e a perspectiva política - em termos de projetos societários prospectivados — do(a) autor(a) ao utilizá-los; tampouco elucidam a própria perspectiva que assumem ao utilizar tais conceitos, o que aparenta uma incorporação de forma naturalizada e um desconhecimento das tensões e disputas presentes em relação aos seus conteúdos no debate feminista contemporâneo. Nesse sentido, além do emprego do conceito gênero, é elucidativa a utilização do debate acerca das relações de poder adotadas principalmente da produção de Foucault, sem problematizar a perspectiva do autor - notadamente vinculada à perspectiva pós-moderna - , como salienta os estudos de Saffioti (2015).

Reconhecemos, também, que há uma incipiente produção de conhecimento na profissão que aborda os movimentos feministas e a luta das mulheres em movimentos mistos e destacamos a importância de ampliar esse debate na categoria. Neste sentido, ressaltamos a relevante iniciativa de criação do Grupo Temático de Pesquisa (GTP) Serviço Social, Relações de Exploração/Opressão de Gênero, Raça/Etnia, Geração, Sexualidades, no XII Encontro Nacional de Pesquisadores em Serviço Social (Enpess), em 2010, com o objetivo de articular, fortalecer e dar visibilidade a essas temáticas. Como observamos, faz-se necessária a ampliação da produção que aborda o movimento feminista, suas lutas e desafios contemporâneos, preocupação que também pode ser observada no planejamento das atividades do GTP. Portanto, ampliar o debate acerca da questão do feminismo — tanto dos conceitos que o particularizam quanto das possibilidades interventivas 
que descortinam nos diferentes espaços sócio-ocupacionais - é um desafio a ser enfrentado pelo Serviço Social.

Recebido em 18/1/18 - Aprovado em 26/2/18

\section{Referências bibliográficas}

ALAGOANO, V. M. O debate do movimento feminista na produção acadêmica do Serviço Social. Dissertação (Mestrado) — Universidade Federal de Juiz de Fora (UFJF). Juiz de Fora, 2016.

CISNE, M. Feminismo, luta de classes e consciência militante feminista no Brasil. Tese (Doutorado) - Universidade Estadual do Rio de Janeiro (UERJ). Rio de Janeiro, 2013. . Feminismo e consciência de classe no Brasil. São Paulo: Cortez, 2014.

DURIGUETTO, M. L.; MONTAÑO, C. Estado, classe e movimento social. São Paulo: Cortez, 2011.

. Produção do conhecimento dos cursos de pós-graduação em Serviço Social sobre lutas, organizações, movimentos sociais e Serviço Social. Temporalis, Brasília, ano 17, n. 34, jul./dez. 2017.

GOLDMAN, W. Mulher, Estado e revolução. São Paulo: Boitempo, 2014.

GONZÁLEZ, A. I. A. As origens e a comemoração do Dia Internacional das Mulheres. São Paulo: Expressão Popular, 2010.

INÁCIO, M. O. A emancipação das mulheres no Projeto Ético-Político do Serviço Social: contribuições e dilemas das relações entre marxismo e feminismo. Tese (Doutorado) - Universidade Federal de Pernambuco CCSA - Programa de Pós-Graduação em Serviço Social. Recife, 2013.

KERGOAT, Danièle. Relações sociais de sexo e divisão sexual do trabalho. In: HIRATA, H. et al. (Orgs). Dicionário crítico do feminismo. São Paulo: UNESP, 2009.

PINTO, C. R. J. Uma história do feminismo no Brasil. São Paulo: Perseu Abramo, 2003. 
SAFFIOTI, H. I. B. A mulher na sociedade de classes: mito e realidade. Petrópolis: Vozes, 1976.

. Gênero, patriarcado, violência. São Paulo: Expressão Popular, 2015.

SCOTT, J. Gênero: uma categoria útil de análise histórica. Educação e Realidade, Porto Alegre, jul./dez. 1995. Disponível em: $<$ https:// edisciplinas.usp.br/pluginfile. php $/ 185058 /$ mod_resource/content $/ 2 / G \% C 3 \% A A n e r o-J o a n \% 20 S c o t t . p d f>$. Acesso em: 23 nov. 2015.

SILVA, I. C. Movimento de mulheres camponesas na trajetória feminista brasileira: uma experiência de luta por direitos e liberdade. Dissertação (Mestrado em Serviço Social) - Programa de Pós-Graduação em Serviço Social - Universidade Federal de Juiz de Fora. Juiz de Fora, 2013.

SOUZA-LOBO. A classe operária tem dois sexos: trabalho, dominação e resistência. São Paulo: Abramo, 2011.

WOOD, E. M. Democracia contra capitalismo: a renovação do materialismo histórico. Tradução: Paulo Cezar Castanha. São Paulo: Boitempo Editorial, 2003. 